Article

\title{
Lysozyme-like Protein Produced by Bifidobacterium longum Regulates Human Gut Microbiota Using In Vitro Models
}

\author{
Mingzhu Du ${ }^{1,2,3}$, Xinqiang Xie ${ }^{3, *}$, Shuanghong Yang ${ }^{1,2,3}$, Ying Li ${ }^{3}{ }^{\oplus}$, Tong Jiang ${ }^{3}$, Juan Yang ${ }^{3}$, Longyan $\mathrm{Li}^{3}$, \\ Yunxiao Huang ${ }^{4}\left(\mathbb{D}\right.$, Qingping $\mathrm{Wu}^{3} \oplus$, Wei Chen ${ }^{1,2}$ and Jumei Zhang ${ }^{3, *}$ \\ 1 State Key Laboratory of Food Science and Technology, Jiangnan University, Wuxi 214122, China; \\ 6190112018@stu.jiangnan.edu.cn (M.D.); 6180112106@stu.jiangnan.edu.cn (S.Y.); \\ chenwei66@jiangnan.edu.cn (W.C.) \\ 2 School of Food Science and Technology, Jiangnan University, Wuxi 214122, China \\ 3 Guangdong Provincial Key Laboratory of Microbial Safety and Health, State Key Laboratory of Applied \\ Microbiology Southern China, Institute of Microbiology, Guangdong Academy of Sciences, \\ Guangzhou 510070, China; liying@gdim.cn (Y.L.); jt0925@stu.scau.edu.cn (T.J.); yj18185238563@163.com (J.Y.); \\ 18868006204@126.cn (L.L.); wuqp203@163.com (Q.W.) \\ 4 College of Life Sciences, South China Agricultural University, Guangzhou 510642, China; \\ hyxiao2000@icloud.com \\ * Correspondence: woshixinqiang@126.com (X.X.); zhangjm926@126.com (J.Z.)
}

Citation: Du, M.; Xie, X.; Yang, S.; Li, Y.; Jiang, T.; Yang, J.; Li, L.; Huang, Y.; Wu, Q.; Chen, W.; et al. Lysozyme-like Protein Produced by Bifidobacterium longum Regulates Human Gut Microbiota Using In Vitro Models. Molecules 2021, 26, 6480. https:// doi.org/10.3390/molecules26216480

Academic Editor: Jean-Marc Sabatier

Received: 26 September 2021

Accepted: 20 October 2021

Published: 27 October 2021

Publisher's Note: MDPI stays neutral with regard to jurisdictional claims in published maps and institutional affiliations.

Copyright: (c) 2021 by the authors. Licensee MDPI, Basel, Switzerland. This article is an open access article distributed under the terms and conditions of the Creative Commons Attribution (CC BY) license (https:// creativecommons.org/licenses/by/ $4.0 /)$.

\begin{abstract}
The extracellular secreted protein of Bifidobacterium longum (B. longum) plays an important role in maintaining the homeostasis of the human intestinal microenvironment. However, the mechanism(s) of interaction remain unclear. Lysozyme is a kind of antibacterial peptide. In this study, the amino acid sequence of a lysozyme-like protein of B. longum based on whole-genome data of an isolate from human gut feces was found. We further predicted functional domains from the amino acid sequence, purified the protein, and verified its bioactivity. The growth of some bacteria were significantly delayed by the 020402_LYZ M1 protein. In addition, the gut microbiota was analyzed via high-throughput sequencing of $16 \mathrm{~S}$ rRNA genes and an in vitro fermentation model, and the fluctuations in the gut microbiota under the treatment of 020402_LYZ M1 protein were characterized. The 020402_LYZ M1 protein affected the composition of human gut microbiota significantly, implying that the protein is able to communicate with intestinal microbes as a regulatory factor.
\end{abstract}

Keywords: Bifidobacterium longum; lysozyme-like protein; bioinformatics; bioactivity; microbiome; balance

\section{Introduction}

Each area of the human gut represents a habitat with unique structure, chemical [1], and biological components [2], which is similar to the river system to some extent [3]. There are trillions of microorganisms [4] and hundreds of distinct bacterial species in the gutsome pathogenic and some beneficial [5]. Millions of years of co-evolution between host and its intestinal microbial ecosystem has formed a symbiotic relationship [6]. Disruptions in gut homeostasis are associated with massive disorders including those affecting circadian rhythmicity, nutritional responses, intestinal diseases, and some metabolic disorders [7], which suggests that the balance of intestinal microbial ecology is crucial for maintaining a healthy immune system [8-10]. B. longum were purported to exert various promoting effects in intestinal dynamic balance and host health [11-13], but the specific mechanism is still obscure. These studies uncovered various molecules that act as important mediators for the establishment of a Bifidobacteria-host communication, such as pili [14], extracellular polysaccharides [15], serpins, TagA [16], BopA [17], etc.

Microbial lysozyme is a kind of hydrolase, also known as muramidase or $N$-acetylmuramide glycanohydrolase. The efficiency of lysozyme in inhabiting gram-positive bacteria depends on its capacity to hydrolyze the $\beta-(1,4)$-glycosidic bond between $N$-acetylmuramic acid and $\mathrm{N}$-acetylglucosamine [18]. The breakage of the peptidoglycan skeleton structure results in 
cell wall damage, and then the bacteria will be ruptured due to the imbalance of osmotic pressure, which leads to the lysis and death of the bacterial cells. The earliest research about the production of lysozyme by microorganisms can be traced back to Nikole's report on the lysis factor of Bacillus subtilis (B. subtilis) $[19,20]$. Subsequently, Fleming discovered a special enzyme in 1922, which came from human saliva and tears [21], and named "lysozyme" because of its lytic ability to dissolve bacterial cell walls. Recently, some research has linked lysozyme with immunity and disease processes [22,23]. Yu showed that Paneth cell lysozyme regulates the relative abundance of mucolytic commensal bacteria and thereby the intestinal inflammatory response [24]. Zhou confirmed that B. longum enhanced mucosal repair, promoted the production of lysozyme, reduced the relative abundance of various pathogens, such as Bacteroidales, Alloprevotella and Bacteroides, and further ameliorated the dysbiosis of the microbiota in WAS rats [25]. These results all reflected the fact that Bifidobacterium maintained the stability of host health and intestinal homeostasis by promoting the secretion of lysozyme came from host cells. Simultaneously, $\mathrm{Wu}$ found that lysozyme affected the microbial composition and quality of grass carp flakes stored at $4{ }^{\circ} \mathrm{C}$ [26], which was consistent with the previous research. In order to prevent the premature release of lysozyme in the stomach, Zhang designed a system targeting delivery of lysozyme to the intestine directly [27], which made sure that lysozyme could work normally. It is noteworthy that this study discovered a gene encoding a lysozyme-like protein in the whole-genome data of B. longum.

In this study, we aimed to explore the role of lysozyme-like protein and its impact on the gut microbiome. Bioinformatic methods were used to analyze the sequence of lysozyme-like protein, followed by expression and purification of that protein subsequently. Functions of the protein were probed by high-throughput sequencing of 16S rRNA and an in vitro model. The results of this study emphasized the lysozyme-like protein derived from $B$. longum and its bioactivity. Besides, the protein modulated the composition of the human gut microbiome, which better understood the specific mechanisms that $B$. longum involved in gut microbiota modulation.

\section{Results and Discussion}

\subsection{Bioinformatic Analysis of Lysozyme-Like Protein}

The sequence encoding a lysozyme-like protein numbered 020402_00271 was found by analyzing the signal peptide and transmembrane domain of the whole-genome data of B. longum 020402. Molecular phylogenetic tree showed that lysozyme-like protein had high sequence homology in different strains, and their evolutionary relationship is relatively close. Besides, 020402_00271 and WP118424932.1 came from the same species (Figure 1a) where the amino acid sequence similarity was 100\% (Figure S1). Based on the Conserved Domain database, the prediction showed that the 020402_00271 protein belongs to the GH25_muramidase superfamily, GH25 superfamily, Acm superfamily, LysM superfamily, and mltD superfamily (Figure $1 \mathrm{~b}$ ). The $\mathrm{N}$-terminal glycosyl hydrolase family 25 (GH25) domain of LysA has sequence similarity with other murein hydrolase catalytic domains, which degrades bacterial cell walls by catalyzing the hydrolysis of 1,4-betalinkages between $N$-acetylmuramic acid and $N$-acetyl-D-glucosamine residues [28,29]. In addition, Acm participated in cell wall/membrane/envelope biogenesis [30], LysM is a widely distributed protein motif for binding to (peptido) glycans [31], and MltD plays a role in muropeptides recycling during cell elongation and/or cell division [32]. 
(a)

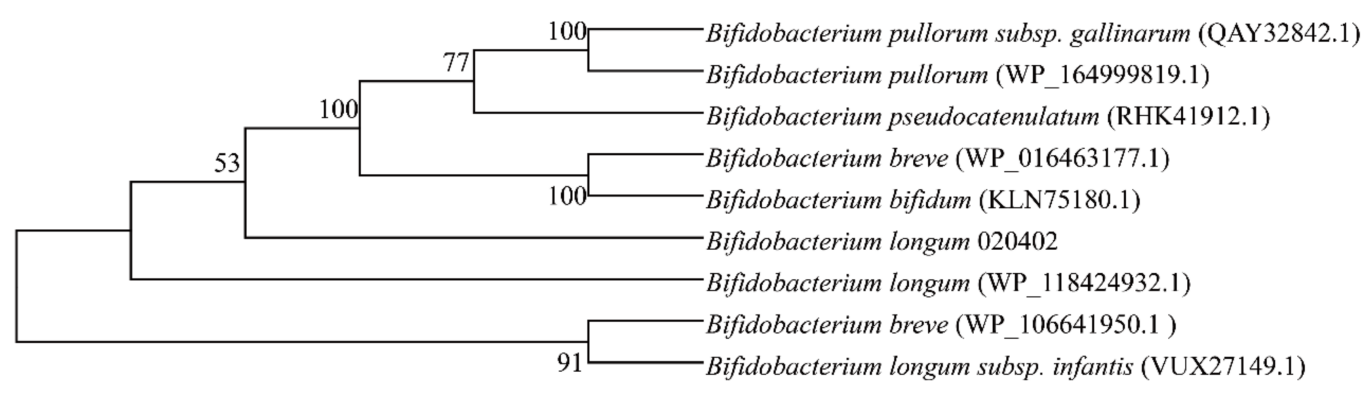

(b)

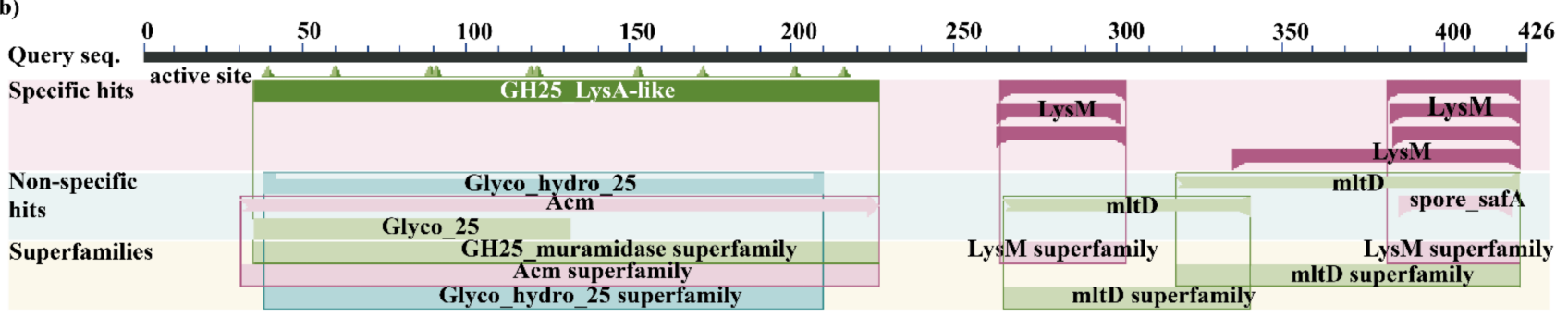

Figure 1. Homology and functional prediction of lysozyme-like protein. (a) Phylogenetic tree of lysozyme-like protein sequence. (b) Conserved domains of lysozyme-like protein.

\subsection{Structure and Purification of 020402_LYZ M1 Protein}

The signal peptide (1-33 amino acids) of 020402_00271 protein was predicted by using SignalP 5.0 and TMHMM 2.0. Besides, the prediction of tertiary structure indicated that the 020402_00271 protein corresponded to 1,4-beta- $N$-Acetylmuramidase M1 (Figures 2a and S2). The value of GMQE was 0.32 and QMEAN was $0.62 \pm 0.06$ in this model, which proved the result was reasonable. By comparing sequences between the 020402_00271 protein and template protein (1jfx.1.A), the length of former sequence was found longer than that of 1jfx.1.A (Figure S3). The extra amino acids of the 020402_00271 protein were simultaneously highlighted in green (Figures 2a and S4). Two pairs of primers were used to amplify the gene encoding a protein without signal peptides (34-426 amino acids) and encoding GH25 LysA-like domain (34-234 amino acids), respectively, followed by vector construction, protein expression, and purification subsequently. Finally, only one protein (34-234 amino acids) was purified successfully and named 020402_LYZ M1. Besides, SDS-PAGE showed a clear and single band (Figure 2b), which meant the 020402_LYZ M1 protein was pure.

The molecular mass of the 020402_LYZ M1 protein coded for 234 amino acid residues was estimated at $25.84 \mathrm{kDa}$, which corresponded to the result of SDS-PAGE. According to the analysis of Phyre2 online software, the 020402_LYZ M1 protein had three binding sites, and its residues were D39, W43, D120, E122, Y153, A175, Y177, Q201, S204, T205, N214, D216, E122, S123, Q155, A156, A175, Q176, Y177, W149, K169, E197, Q226, A229, and Y230. In addition, the active sites of this protein were D39, K60, Y89, Y91, D120, E122, Y153, W173, Q201, and D216 (Figure 2a). Both binding sites and active sites were conservative highly in the 020402_LYZ M1 protein (Figure S5), which meant the 020402_LYZ M1 protein maintained the functions of these conserved domains. 
(a)

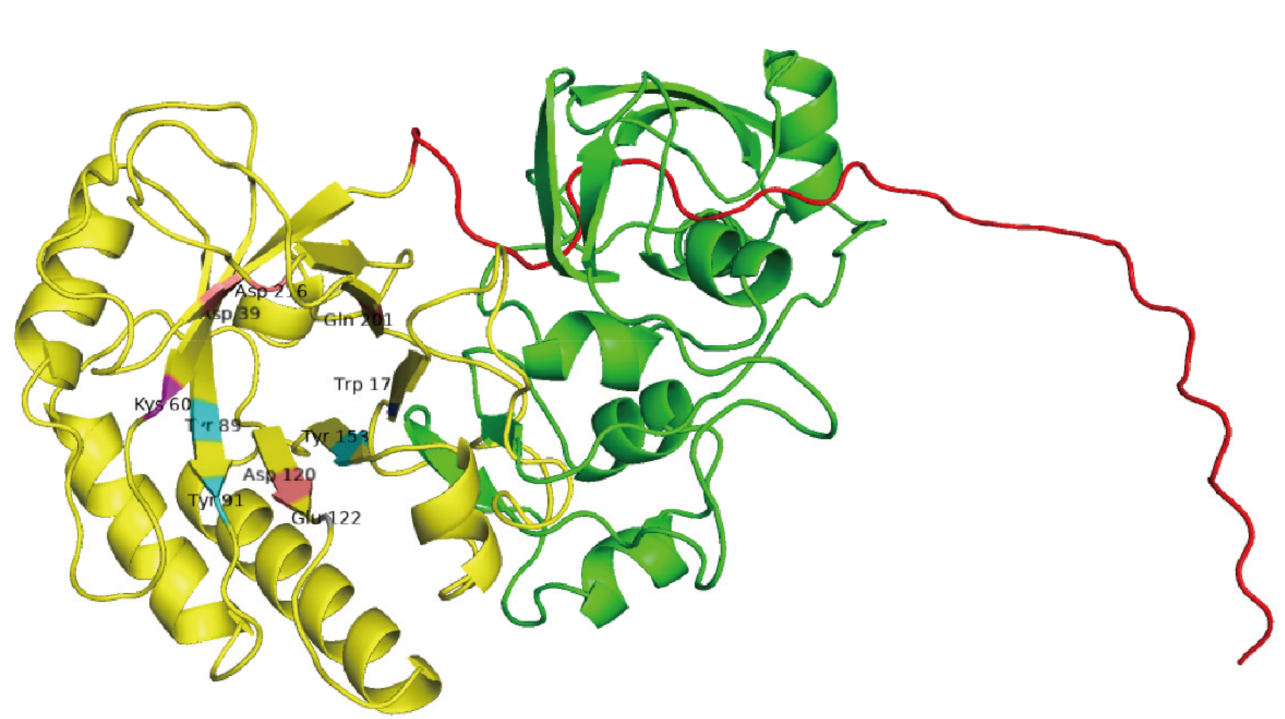

(b) M 020402 LYZ M1

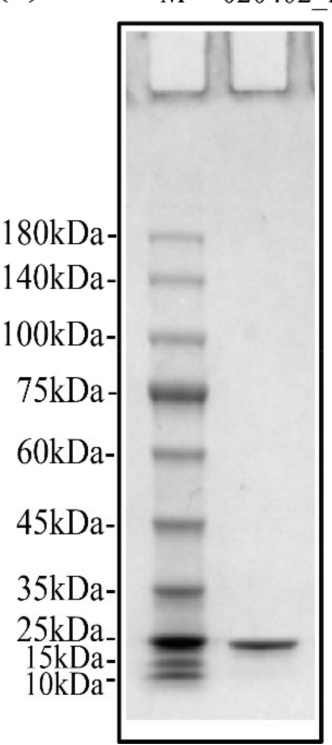

Figure 2. Tertiary structure prediction and gel map. (a) Homology analysis and model prediction of the $020402 \_00271$ protein. (b) The SDS-PAGE analysis of 020402_LYZ M1 protein, M: marker.

\subsection{Bioactivity of 020402_LYZ M1 Protein}

The inhibition of bacterial growth by B17_2 was explored using two gram-positive strains, B. subtilis ATCC 6633 and S. aureus ATCC 25923. The time-inhibition curve could provide information about the kinetics of bacterial growth [33]. As for B. subtilis ATCC 6633, the curve of the control group showed a significant increase after $3 \mathrm{~h}$. However, the experiment group treated with the 020402_LYZ M1 protein went up from $4 \mathrm{~h}$ to $9 \mathrm{~h}$, reaching a plateau period after $9 \mathrm{~h}$ (Figure 3a), which indicated that 020402_LYZ M1 protein delayed the logarithmic growth of $B$. subtilis ATCC 6633 for one hour. The bacterial suspension of B. subtilis ATCC 6633 cultured for $9 \mathrm{~h}$ were cultured onto MRS agar plates. Compared with the control group, the results of group treated with 020402_LYZ M1 showed the same tendency, with fewer viable bacteria (Figure 3b). Similarly, 020402_LYZ M1 also affected the growth of $S$. aureus ATCC 25923. Although the two groups entered the logarithmic growth phase after $2 \mathrm{~h}$ of fermentation, the growth curve of the control group rose more significantly than that of treated with 020402_LYZ M1 (Figure 3c). Dilution coating plate experiments were also carried out with S. aureus ATCC 25923 cultivated for $9 \mathrm{~h}$. The trend was the same as the time-inhibition curve, where the number of viable bacteria reduced sharply with 020402_LYZ M1 treatment (Figure 3d). These results all illustrated that 020402_LYZ M1 had antibacterial bioactivity; that is, it only delayed bacterial growth, which is consistent with the discovery of Derde [34]. 
(a)

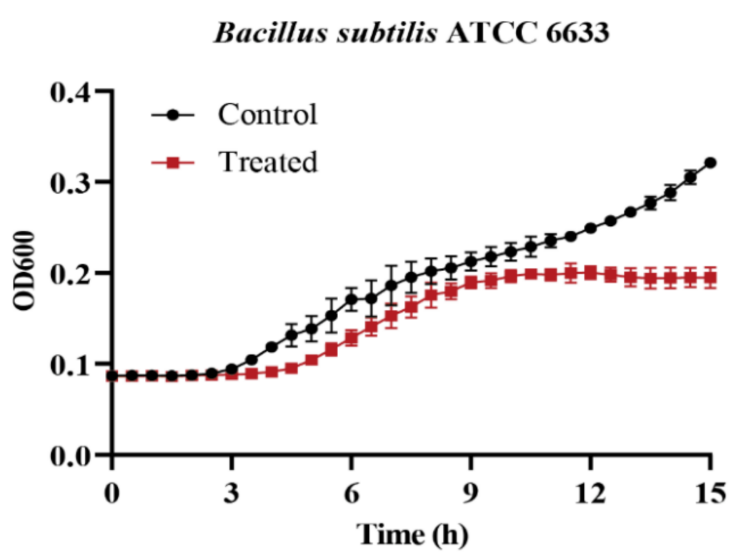

(c)

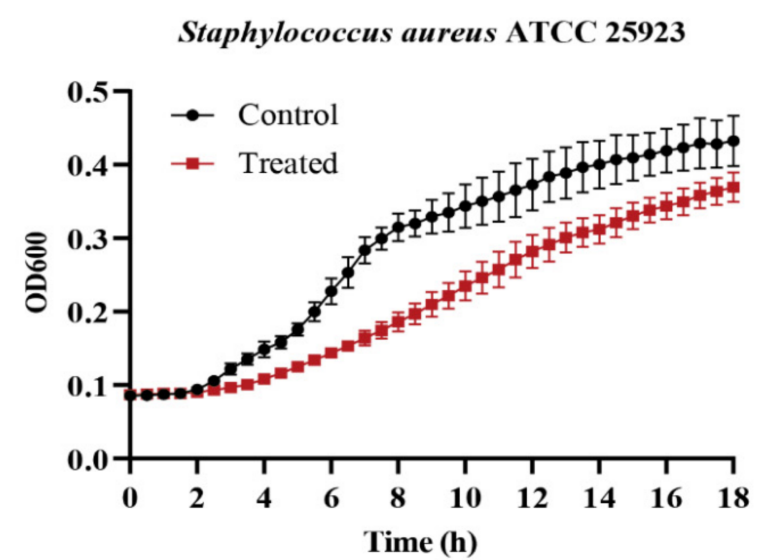

(b)
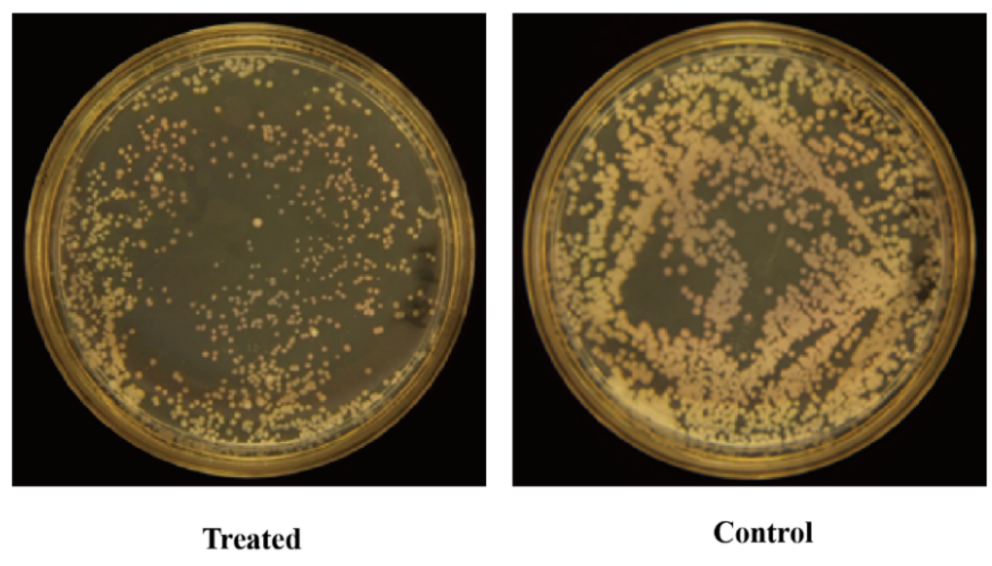

(d)

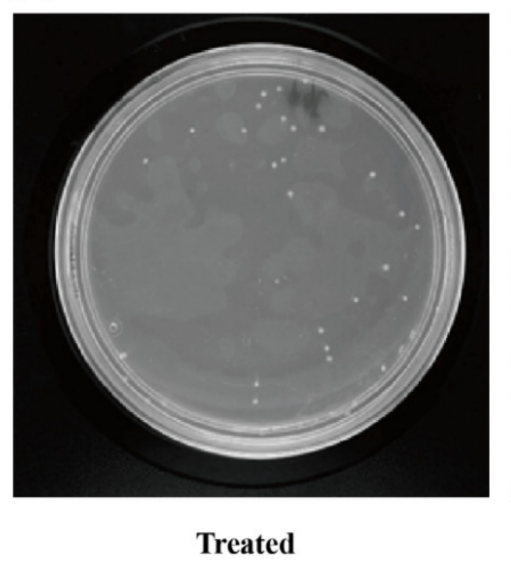

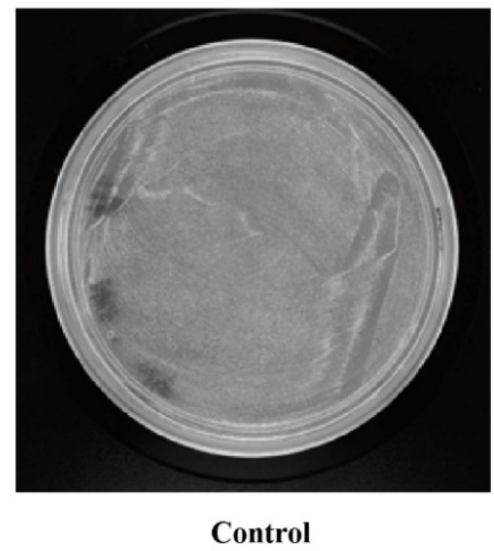

Figure 3. Bioactivity of the 020402_LYZ M1 protein. (a) The growth curves of B. subtilis ATCC 6633. (b) The dilution coating plate experiment of B. subtilis ATCC 6633. (c) The growth curves of S. aureus ATCC 25923. (d) The dilution coating plate experiment of S. aureus ATCC 25923.

\subsection{2_LYZ M1 Protein Regulates Gut Microbiota}

In order to verify the ablity of the 020402_LYZ M1 protein to regulate the intestinal microbiome, seven time points were selected to track the change of composition of the human intestinal microbiome. Observed OTUs are equal to the number of species in each sample: the more OTUs, the greater the number of species [35]. The Shannon index was used to estimate the microbial diversity in a sample: the larger the Shannon value, the higher the community diversity [36]. Compared with $0 \mathrm{~h}$ fermentation time, the observed OTUs and Shannon index were reduced at each time point after using TPY medium, which indicated that the single medium (TPY broth) cultivated all bacteria unsuccessfully and caused the loss of specific bacteria. Similar to the study by Namai, the use of a single medium could lead to the disappearance of a large number of gut microbes [37], which is a limitation that should be overcomed in future studies. When it comes to $\alpha$-diversity, the species diversity of feces notably decreased after treatment with the 020402_LYZ M1 protein for $24 \mathrm{~h}$. However, there was no significant difference between the treatment group and the control group after $48 \mathrm{~h}$, showing that the 020402_LYZ M1 protein could not kill microorganisms and only delayed the growth of certain bacteria for a period of time (Figure 4a). It is noteworthy that the community diversity of gut microbes flustered throughout the whole fermentation process. In addition, the Shannon index of the experimental group treated with the 020402_LYZ M1 protein for $48 \mathrm{~h}$ increased, while the 
species diversity of the control group decreased after $48 \mathrm{~h}$ of fermentation, which indicated that the 020402_LYZ M1 protein had the ability to maintain species diversity (Figure 4b).

The results of high-throughput sequencing of $16 \mathrm{~S}$ rRNA genes showed that the microbial communities of all samples covered 9 phyla, 14 classes, 25 orders, 55 families, and 80 genera. The gut microbiota compositions at the phylum, family, and genus levels were characterized as follows: at phylum level, the gut microbiotas fluctuated obviously from $8 \mathrm{~h}$ to $36 \mathrm{~h}$. Compared with the control group, the relative abundance of Firmicutes increased in the group treated with 020402_LYZ M1 protein during the whole period, expect for $0 \mathrm{~h}$ and $48 \mathrm{~h}$, while the relative abundance of Proteobacteria decreased. In contrast, the gap in the relative abundance of Proteobacteria was not significant between the treatment group and the control group by the end of the period, which indicated that the 020402_LYZ M1 protein could inhibit the colonization and expansion of the Proteobacteria within a certain period (Figure 4c).

When it comes to family level, the top ten of the gut microbial relative abundances can be listed as follows: Streptococcaceae, Enterobacteriaceae, Leuconostocaceae, Lactobacillaceae, Lachnospiraceae, Bifidobacteriaceae, Ruminococcaceae, Clostridiaceae, Clostridiales, and Bacteroidaceae. The relative abundance of Streptococcaceae increased gradually, while the relative abundance of Enterobacteriaceae decreased after treatment with the 020402_LYZ M1 protein, which was consistent with the tendency of phylum-level. Besides, the relative abundance of Lactobacillaceae reached the peak in $36 \mathrm{~h}$, showing that Lactobacillaceae had entered the logarithmic growth phase after $36 \mathrm{~h}$, which had a guiding significance of isolation and cultivation of Lactobacillaceae in the future. However, the relative abundance of Lactobacillaceae decreased after treatment with the 020402_LYZ M1 protein (Figure 4d).

At the genus level, the relative abundance of Streptococcus ranked first, expect for $0 \mathrm{~h}$ (Figure 4e). Compared with the relative abundances between treatment group and the control group at this level, the relative abundances of Streptococcus, Leuconostocaceae, and Clostridiaceae in the former group increased, while the relative abundances of Lactobacillus and Bifidobacterium decreased. Besides, the same trends were showed in a cluster heat map (Figure 4f). It is common that Bifidobacterium and Lactobacillus are beneficial to human health, however, some studies showed that Bifidobacterium and Lactobacillus were risk factors in the fecal microbiota transplantation (FMT) and lactose intolerance (LI) [38-41]. Treatment of LI can include a low-lactose diet [42], lactase supplementation [43], probiotics [44], and colonic adaptation by prebiotics [45], such as galacto-oligosaccharides (GOS) [46], in which lactase is used to hydrolyse lactose into galactose and glucose to alleviate lactose intolerance symptoms. It is interesting that the kinds of protein added to dairy products are widely available and considered safe. However, residual side proteolytic activity of lactase can degenerate casein and impair taste, especially after long storage [47]. As for the impact of the gut microbiome on the occurrence of gut-related LI symptoms, Gois provided evidence that specific gut symptoms, experienced by lactose intolerance (LI) patients, might be the result of Bifidobacterium abundance in the gut, rather than a direct effect of lactose intake [41], which supports initial reports where metabolic products of lactose-fermenting bacteria may be related to LI symptom occurrence [48-50]. Notably, the abundance of Bifidobacterium decreased by using the 020402 LYZ_M1 protein in this study, which inspired us to investigate whether the ability of the 020402 LYZ_M1 protein affects the Bifidobacterium abundance in LI individuals. These results reflected that the 020402 LYZ_M1 protein was involved in gut microbiota modulation in this study. Simultaneously, a healthy gut microbiome relies on high richness and biodiversity [51]. If the dominant positions of the bacteria reported as probiotics are emphasized blindly, the balance of intestinal microecology will be broken. 
(a)
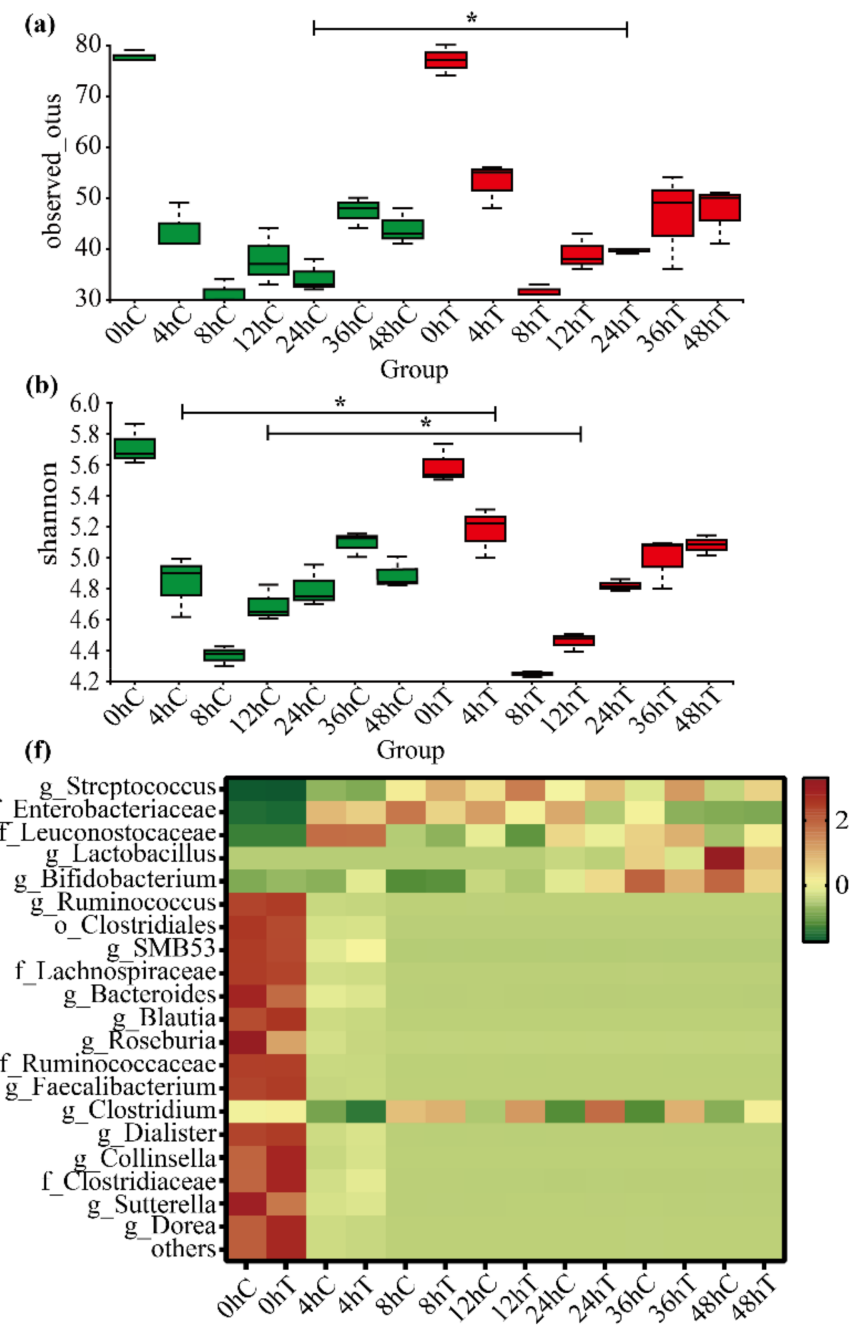

(c)

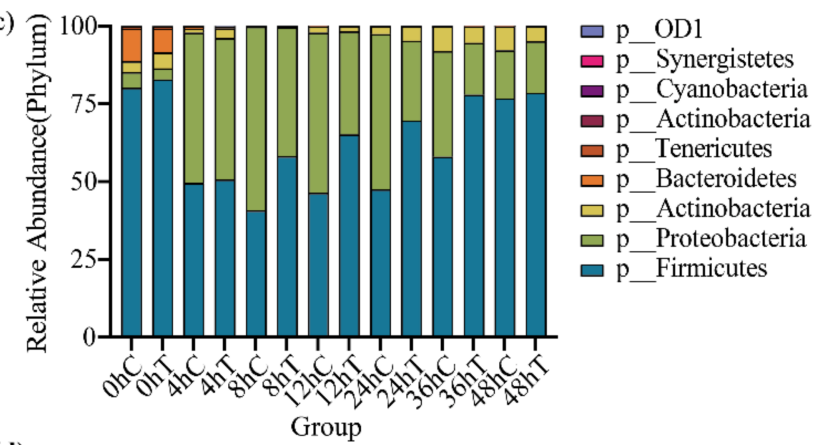

(d)
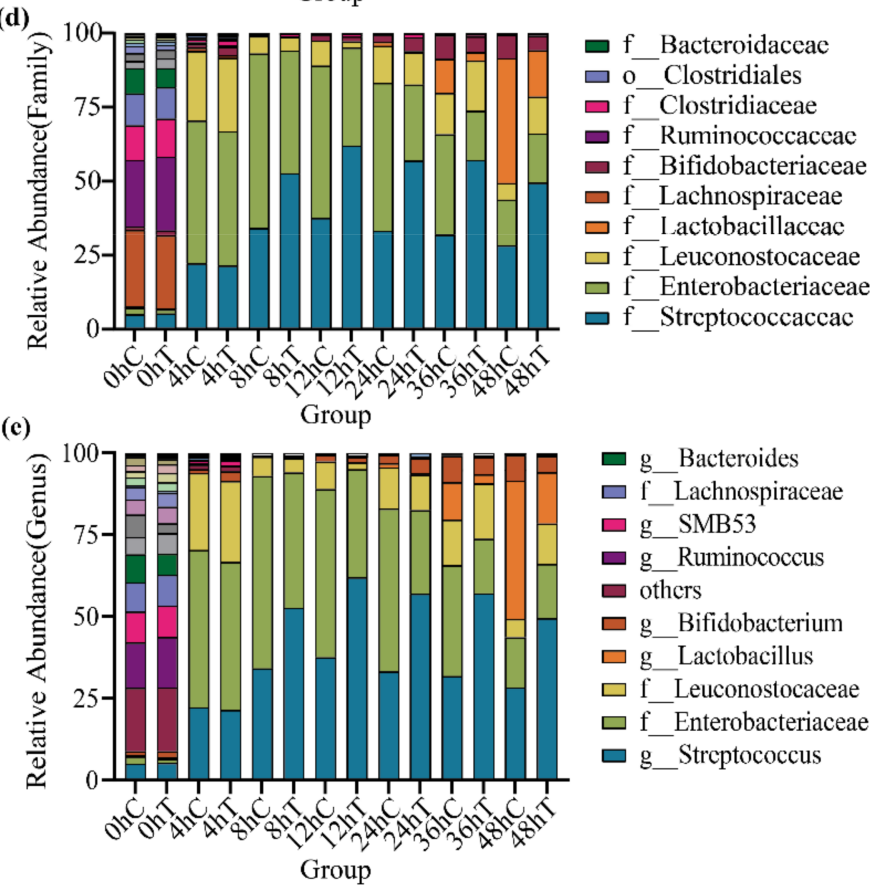

Figure 4. The 020402_LYZ M1 protein modulates the composition of gut microbiota. The numbers of replicated samples in this figure are as follows: $0 \mathrm{~h}(n=3), 4 \mathrm{~h}(n=3), 8 \mathrm{~h}(n=3), 12 \mathrm{~h}(n=3), 24 \mathrm{~h}(n=3), 36 \mathrm{~h}(n=3), 48 \mathrm{~h}(n=3)$; C: control group; T: treatment group. (a) Observed Otus. (b) Shannon index. (c) Top eight of the relative abundances of gut microbiota at Phylum level. (d) Top ten at Family level. (e) Top ten at Genus level. (f) Heatmap at Genus level. ${ }^{*} p<0.05$, $T$-test.

\subsection{2_LYZ M1 Protein Restrain the Growth of Lactobacillus}

The flora maintains the steady state of the microenvironment with their proportions in the intestine respectively. In order to verify the ability of the 020402_LYZ M1 protein to inhibit the overgrowth of Lactobacillus, Lactobacillus fermentum, Lactobacillus paracasei, and Lactobacillus delbrueckii, three strains were isolated from the samples from the in vitro fermentation experiment and treated with the 020402_LYZ M1 protein. Compared with the control group, the 020402_LYZ M1 protein reduced the bacterial mass and delayed the time to enter the logarithmic phase of L. fermentum, L. paracasei, and L. delbrueckii for $4 \mathrm{~h}, 6 \mathrm{~h}$, and $5 \mathrm{~h}$, respectively (Figure $5 \mathrm{a}-\mathrm{c}$ ). These conclusions corresponded to the previous experiment, where the 020402_LYZ M1 protein reduced the relative abundance of Lactobacillus and inhibited the excessive growth of Lactobacillus (Figure $4 \mathrm{f}$ ). 

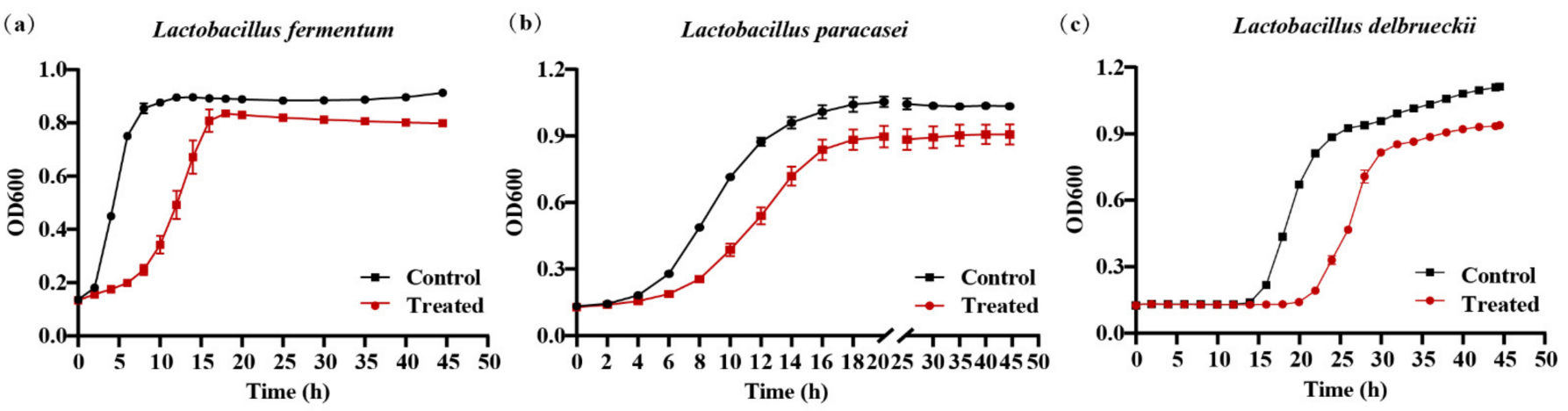

Figure 5. 020402_LYZ M1 affects the growth of Lactobacillus. (a) Growth curve of Lactobacillus fermentum. (b) Growth curve of Lactobacillus paracasei. (c) Growth curve of Lactobacillus delbrueckii.

\section{Materials and Methods}

\subsection{Bacterial Isolates and Sequencing}

B. longum 020402 was isolated from human fecal samples, coming from Jiaoling, Guangdong, China. Bacterial DNA was extracted by HiPure Microbial DNA Kit (Magen Biotech, Guangzhou, China) according to the manufacturer's instructions. Its wholegenome data were obtained by using the Illumina NextSeq instrument owned by the Institute of Microbiology, Guangdong Academy of Sciences.

\subsection{Analysis of Sequence Homology}

In the National Center for Biotechnology Information (NCBI), https:/ /www.ncbi. nlm.nih.gov / (accessed on 8 August 2021), Basic Local Alignment Search Tool (BLASTp) was used to search for homologous sequences of protein in different species and MEGAX software (Mega Limited, Auckland, New Zealand)was used to construct a NeighborJoining evolutionary tree with 1000 bootstraps, and then the following tools were used for analysis: CLUSTALW https:/ / www.genome.jp/tools-bin/clustalw (accessed on 8 August 2021)for sequence alignment and ESPript https:/ / espript.ibcp.fr/ESPript/cgi-bin/ESPript. cgi (accessed on 8 August 2021) for presentation of the results.

\subsection{Analysis of Structure and Function}

The following tools were used to predict each element: SignallP $5.0 \mathrm{http}: / / \mathrm{www}$. cbs.dtu.dk/services/SignalP (accessed on 8 August 2021) for the N-terminal signal peptide prediction, TMHMM 2.0 http:/ / www.cbs.dtu.dk/services/TMHMM (accessed on 8 August 2021) for transmembrane region prediction, and ProtParam https:/ /web.expasy. org/protparam (accessed on 8 August 2021) for physical and chemical properties prediction. Besides, Conservative domain database Home-Conserved Domains-NCBI (nih.gov) (accessed on 15 August 2018) was used to predict functional domains. The three-dimensional structures and the binding sites of the protein were predicted by using SWISS-MODEL https:/ / swissmodel.expasy.org (accessed on 10 August 2021) and phyre2 http:/ / www.sbg.bio.ic.ac.uk/phyre2 (accessed on 11 August 2021) accessed on respectively. PyMOL version 2.5.0 was used to analyze the structural modeling.

\subsection{Gene Cloning of Target Protein}

The whole-genome DNA extracted from B. longum 020402 was used as a template, and two pairs of primers were designed to clone the target gene. The gene encoding a protein without signal peptide (34-426 amino acids) was cloned by using primer pair 1 (F: 5'-AAAAAACATATGGTGGCGGATATGCAGGGCATTG-3'; R: 5'-GTGGTGCTC GAGTCGGTAGTGCAGCACTTCGCCGGG-3'). The gene encoding GH25 LysA-like domain (34-234 amino acids) was amplified by using primer pair 2 (F: 5'-AATTATCCATGGCAG TGGCGGATATGCAGGGCATTG-3'; R: 5'-GTGGTGCTCGAGGTCGCCCTGCGCGTACG 
CGTC- $\left.3^{\prime}\right)$. The resulting gene fragment and plasmid pET28a (+) were digested with restriction endonucleases (NEB, Ipswich, MA, USA), and then the target fragment was recovered by using purification kit (Omega bio-tek, Norcross, GA, USA) and gel recovery kit (Omega bio-tek, Norcross, GA, USA). After that, the target fragment and the plasmid were ligated by using T4 ligase (NEB, Ipswich, MA, USA) and subsequently transformed into Escherichia coli (E. coli) DH5 $\alpha$ (Sangon Biotech, Shanghai, China). The positive colons were screened by amplification with primer pair (T7: 5'-TAATACGACTCACTATAGGG-3'; T7-Term: $5^{\prime}$-GCTAGTTATTGCTCAGCGG-3') and Sanger sequencing. If the target gene had no base mutations, the vector of pET-28a (+)/target gene was constructed successfully.

\subsection{Heterologous Expression and Purification of Target Protein}

Next, the target protein overexpression was induced in E. coli BL21 (DE3) (Sangon Biotech, Shanghai, China). Afterwards, the cells were collected by centrifugation $\left(10,000 \times \mathrm{g}, 20 \mathrm{~min}, 4^{\circ} \mathrm{C}\right)$, dissolved in $35 \mathrm{~mL}$ of lysis buffer (1M NaCI, $50 \mathrm{mM}$ phosphate buffer saline, $70 \mathrm{mM}$ Imidazole, $1 \mathrm{mg} / \mathrm{mL}$ lysozyme, $\mathrm{pH}=7.6$ ), and stored at $-80{ }^{\circ} \mathrm{C}$ until use.

According to Xie's methods [52], we took out the bacterial cells stored at $-80{ }^{\circ} \mathrm{C}$, followed by ultrasonic fragmentation at $0{ }^{\circ} \mathrm{C}$. Then, the supernatant was harvested by centrifugation $\left(15,000 \times \mathrm{g}, 30 \mathrm{~min}, 4^{\circ} \mathrm{C}\right)$, filtrated by $0.8 \mu \mathrm{m}$ filters, and stored at $4{ }^{\circ} \mathrm{C}$ until use. The filtrated supernatant was loaded on a $5 \mathrm{~mL}$ His Trap nickel column (HisTrap TM FF, GE Healthcare, Chicago, IL, USA) pre-equilibrated with the lysis buffer (1M NaCI, $50 \mathrm{mM}$ phosphate buffer saline, $70 \mathrm{mM}$ Imidazole, $\mathrm{pH}=7.6$ ). After that, the target protein with His-tag were collected by washing buffer $(150 \mathrm{mM} \mathrm{NaCI}, 50 \mathrm{mM}$ phosphate buffer saline, $200 \mathrm{mM}$ Imidazole, $\mathrm{pH}=7.2$ ). In order to concentrate the target protein and remove salt ions from that, the collected protein was transferred to a MWCO $10 \mathrm{KDa}$ ultrafiltration tube (Millipore, Burlington, MA, USA), mixed with exchange buffer (100 mM NaCI, $50 \mathrm{mM}$ phosphate buffer saline, $10 \%$ glycerin, $\mathrm{pH}=7.2)$, and centrifuged $(4000 \mathrm{rpm}, 40 \mathrm{~min}$, $4{ }^{\circ} \mathrm{C}$ ), which was repeated twice. Finally, the target protein was mixed with $20 \%$ glycerol, divided into $1.5 \mathrm{~mL}$ tubes, and stored at $-80{ }^{\circ} \mathrm{C}$ until use. Lysis buffer, $\mathrm{ddH}_{2} \mathrm{O}, \mathrm{EDTA}$ solution, $\mathrm{ddH}_{2} \mathrm{O}$, nickel sulfate, and $\mathrm{dd}_{2} \mathrm{O}$ were subsequently used to clean the nickel column, which was finally stored at $4{ }^{\circ} \mathrm{C}$. Sodium dodecyl sulfate-polyacrylamide gel electrophoresis (SDS-PAGE) was used to verify the purity of the target protein.

\subsection{Evaluation of Bioactivity}

The bacterial cells of Bacillus subtilis ATCC 6633, Staphylococcus aureus ATCC 25923, Lactobacillus fermentum, Lactobacillus paracasei, and Lactobacillus delbrueckii were collected, when reaching to the logarithmic phase. Then, $10^{6} \mathrm{CFU} / \mathrm{mL}$ bacterial suspensions were prepared. After that, 2.5\% 020402_LYZ M1 protein or a mixture of exchange buffer ( $100 \mathrm{mM}$ $\mathrm{NaCI}, 50 \mathrm{mM}$ phosphate buffer saline, $10 \%$ glycerin, $\mathrm{pH}=7.2$ ) with $20 \%$ glycerol were administered to the treatment groups and the counterparts respectively, and all groups were incubated at $37^{\circ} \mathrm{C}$ for $48 \mathrm{~h}$. The $\mathrm{OD}_{600}$ reading was measured by using a microplate reader, and three parallel entries of the kinetic growth information were recorded every $30 \mathrm{~min}$. Time-inhibition curves were derived to identify the time point at which inhibition was observed after 020402_LYZ M1 protein treatment, and dilution coating plate experiment was used to observe the number of viable bacteria. In addition, the following media were used for bacterial culturing: MRS medium (Huankai, Guangzhou, China) for Bacillus subtilis ATCC 6633, LB medium (Huankai, Guangzhou, China) for Staphylococcus aureus ATCC 25923, TPY medium (Hopebio, Qingdao, China) for Lactobacillus fermentum, Lactobacillus paracasei, and Lactobacillus delbrueckii.

\subsection{In Vitro Fermentation Experiment and Illumina MiSeq Sequencing}

A stool sample was collected from a healthy donor via fecal microbiota transplantation (FMT), which was approved by the ethics committee of the First Affiliated Hospital of Guangdong Pharmaceutical University (reference 2017-98) [53]. About $0.5 \mathrm{~g}$ of feces were 
weighed and placed on ice, then resuspended with $50 \mathrm{~mL} 0.9 \%$ stroke-physiological saline solution (SPSS). $1 \%$ of the mixture was inoculated into TPY broth after mixing well and the culture medium containing feces was divided into two parts, the treatment group $(\mathrm{T})$ and the control group $(\mathrm{C})$, with three parallel entries for each group. The treatment group was administered $2.5 \%$ of $020402 \_L Y Z$ M1 protein, and the control group was treated with $2.5 \%$ of a mixture of exchange buffer $(100 \mathrm{mM} \mathrm{NaCI}, 50 \mathrm{mM}$ phosphate buffer saline, $10 \%$ glycerin, $\mathrm{pH}=7.2$ ) with $20 \%$ glycerol. Samples were collected at different ferment times ( $0 \mathrm{~h}, 4 \mathrm{~h}, 8 \mathrm{~h}, 12 \mathrm{~h}, 24 \mathrm{~h}, 36 \mathrm{~h}$, and $48 \mathrm{~h}$ ), centrifuged to remove the supernatant, and divided into two shares evenly. One share of the sample was mixed with $30 \%$ glycerol and stored at $-80{ }^{\circ} \mathrm{C}$ until use, and the other sample were stored in dry ice and sent to a commercial laboratory (Genewiz, Inc., Suzhou, China) for high-throughput sequencing of 16S rRNA genes. The DNA templates were extracted from each sample, the V4-V5 region of the $16 \mathrm{~S}$ rRNA genes were amplified, and the PCR products were sequenced by using MiSeq (Illumina, Inc., San Diego, CA, USA). The original binary base-calling data obtained by using sequencing were converted into pass filtering $(\mathrm{PF})$ or raw sequence data by Illumina bcl2fastq software (Illumina, San Diego, CA, USA). Barcodes were removed from raw data by using Perl script and low-quality data were removed by using Trimmomatic version 0.39 [54].

\subsection{Isolation of Lactobacillus}

Based on in vitro ferment experiment described in Section 3.7, TPY medium was used for separation and cultivation of Lactobacillus from the samples stored at $-80^{\circ} \mathrm{C}$. Firstly, the samples were diluted with $0.9 \%$ SPSS to obtain serial bacterial suspension (10-fold) from $10^{-1}$ to $10^{-6}$ dilution, $100 \mu \mathrm{L}$ of that were cultured onto TPY agar plates until dry, and cultured with 3 parallels in anaerobic condition at $37^{\circ} \mathrm{C}$ for $48 \mathrm{~h}$. According to the different colonial morphologies, single colonies were selected randomly and streaked on TPY agar plates twice. After that, single colonies were inoculated into TPY broth until obvious turbidity was observed, collected, and identified by Sanger sequencing.

\subsection{Statistical Analysis}

$T$-test was used to evaluate the difference among all groups and the $p$ values $<0.05$ were considered significant. All data are presented in mean \pm S.D. The graphic illustrations were generated with the GraphPad Prism 9 (GraphPad Software, San Diego, CA, USA).

\section{Conclusions}

This study characterized the amino acid sequence of a lysozyme-like protein of B. longum based on whole-genome data of an isolate from human gut feces. The sequence showed high homology with other of that and its GH25 LysA-like domain is highly conservative. Then, we expressed and purified the protein by using a gene encoding lysozyme-like protein partly, which was the bioactive protein with delaying the growth of some bacteria and modulating the composition of human gut microbiome in vitro. In summary, these results revealed the bioactivity of lysozyme-like protein and demonstrated changes in diversity of the human gut microbiome by using that from B. longum, which better understood the specific mechanisms that $B$. longum involved in gut microbiota modulation. Besides, it also provided a potential option for treatment of lactose intolerance. Future direction will include the exploration of targeted delivery of lysozyme-like protein and the proper resolution of lactose intolerance.

Supplementary Materials: The following are available online, Figure S1: Multiple sequence alignment of lysozyme-like protein from nine Bifidobacterium strains, Figure S2: Prediction of tertiary structure of 020402_00271 protein by SWISS-MODEL, Figure S3: Sequence alignment between 020402_00271 protein and 1jfx.1.A, Figure S4: Amino acids sequence of 020402_00271 protein, Figure S5: Analysis of conserved sites of 020402_LYZ M1. 
Author Contributions: Conceptualization, X.X., J.Z. and W.C.; methodology, X.X. and M.D.; software, X.X., M.D. and S.Y.; formal analysis, M.D. and Y.L.; investigation, M.D. and S.Y.; resources, M.D. and J.Y.; data curation, M.D., T.J., Y.H. and L.L.; writing-original draft preparation, M.D. and X.X.; writing-review and editing, X.X., J.Z. and W.C.; visualization, M.D. and X.X.; supervision, M.D., X.X. and S.Y.; project administration, X.X. and J.Z.; funding acquisition, X.X., J.Z. and Q.W. All authors have read and agreed to the published version of the manuscript.

Funding: This work was founded by the National Natural Science Foundation of China (21977020), Key Research and Development Plan of Guangdong Province (2018B020205002), Guangdong Provincial Key Laboratory (2020B121201009), the Department of Science and Technology of Guangdong Province (2019QN01N107), and GDAS' Project of Science and Technology Development (2020GDASYL20200102003).

Institutional Review Board Statement: The studies involving human participants were reviewed and approved by the Ethics Committee of The First Affiliated Hospital of Guangdong Pharmaceutical University (reference 2017-98).

Informed Consent Statement: Informed consent was obtained from all subjects involved in the study.

Data Availability Statement: Data will be available on the reasonable request from the corresponding author.

Conflicts of Interest: The authors declare no conflict of interest.

Sample Availability: Not applicable.

\section{References}

1. Milani, C.; Duranti, S.; Bottacini, F.; Casey, E.; Turroni, F.; Mahony, J.; Belzer, C.; Delgado Palacio, S.; Arboleya Montes, S.; Mancabelli, L.; et al. The First Microbial Colonizers of the Human Gut: Composition, Activities, and Health Implications of the Infant Gut Microbiota. Microbiol. Mol. Biol. Rev. 2017, 81. [CrossRef] [PubMed]

2. Mafra, D.; Borges, N.; Alvarenga, L.; Esgalhado, M.; Cardozo, L.; Lindholm, B.; Stenvinkel, P. Dietary Components That May Influence the Disturbed Gut Microbiota in Chronic Kidney Disease. Nutrients 2019, 11, 496. [CrossRef]

3. Buddington, R. Using Probiotics and Prebiotics to Manage the Gastrointestinal Tract Ecosystem. In Prebiotics and Probiotics Science and Technology; Charalampopoulos, D., Rastall, R.A., Eds.; Springer: New York, NY, USA, 2009; pp. 1-31.

4. Sender, R.; Fuchs, S.; Milo, R. Are We Really Vastly Outnumbered? Revisiting the Ratio of Bacterial to Host Cells in Humans. Cell 2016, 164, 337-340. [CrossRef]

5. Van Treuren, W.; Dodd, D. Microbial Contribution to the Human Metabolome: Implications for Health and Disease. Annu. Rev. Pathol. 2020, 15, 345-369. [CrossRef]

6. Alessandri, G.; Ossiprandi, M.C.; MacSharry, J.; van Sinderen, D.; Ventura, M. Bifidobacterial Dialogue With Its Human Host and Consequent Modulation of the Immune System. Front. Immunol. 2019, 10, 2348. [CrossRef]

7. Zheng, D.; Liwinski, T.; Elinav, E. Interaction between microbiota and immunity in health and disease. Cell Res. 2020, 30, 492-506. [CrossRef] [PubMed]

8. Michaudel, C.; Sokol, H. The Gut Microbiota at the Service of Immunometabolism. Cell Metab. 2020, 32, 514-523. [CrossRef]

9. Nganou-Makamdop, K.; Talla, A.; Sharma, A.; Darko, S.; Ransier, A.; Laboune, F.; Chipman, J.; Beilman, G.; Hoskuldsson, T.; Fourati, S.; et al. Translocated microbiome composition determines immunological outcome in treated HIV infection. Cell 2021, 184, 3899-3914.e16. [CrossRef] [PubMed]

10. Ost, K.S.; O'Meara, T.R.; Stephens, W.Z.; Chiaro, T.; Zhou, H.; Penman, J.; Bell, R.; Catanzaro, J.R.; Song, D.; Singh, S.; et al. Adaptive immunity induces mutualism between commensal eukaryotes. Nature 2021, 596, 114-118. [CrossRef]

11. Pinto-Sanchez, M.I.; Hall, G.B.; Ghajar, K.; Nardelli, A.; Bolino, C.; Lau, J.T.; Martin, F.P.; Cominetti, O.; Welsh, C.; Rieder, A.; et al. Probiotic Bifidobacterium longum NCC3001 Reduces Depression Scores and Alters Brain Activity: A Pilot Study in Patients With Irritable Bowel Syndrome. Gastroenterology 2017, 153, 448-459.e448. [CrossRef]

12. Schroeder, B.O.; Birchenough, G.M.H.; Ståhlman, M.; Arike, L.; Johansson, M.E.V.; Hansson, G.C.; Bäckhed, F. Bifidobacteria or Fiber Protects against Diet-Induced Microbiota-Mediated Colonic Mucus Deterioration. Cell Host Microb. 2018, 23, $27-40 . e 27$. [CrossRef] [PubMed]

13. Toscano, M.; De Grandi, R.; Stronati, L.; De Vecchi, E.; Drago, L. Effect of Lactobacillus rhamnosus HN001 and Bifidobacterium longum BB536 on the healthy gut microbiota composition at phyla and species level: A preliminary study. World J. Gastroenterol. 2017, 23, 2696-2704. [CrossRef]

14. Bottacini, F.; van Sinderen, D.; Ventura, M. Omics of bifidobacteria: Research and insights into their health-promoting activities. Biochem. J. 2017, 474, 4137-4152. [CrossRef]

15. Milani, C.; Mangifesta, M.; Mancabelli, L.; Lugli, G.A.; Mancino, W.; Viappiani, A.; Faccini, A.; van Sinderen, D.; Ventura, M.; Turroni, F. The Sortase-Dependent Fimbriome of the Genus Bifidobacterium: Extracellular Structures with Potential To Modulate Microbe-Host Dialogue. Appl. Environ. Microbiol. 2017, 83. [CrossRef] 
16. Guglielmetti, S.; Zanoni, I.; Balzaretti, S.; Miriani, M.; Taverniti, V.; De Noni, I.; Presti, I.; Stuknyte, M.; Scarafoni, A.; Arioli, S.; et al. Murein lytic enzyme TgaA of Bifidobacterium bifidum MIMBb75 modulates dendritic cell maturation through its cysteineand histidine-dependent amidohydrolase/peptidase (CHAP) amidase domain. Appl. Environ. Microbiol. 2014, 80, 5170-5177. [CrossRef] [PubMed]

17. Guglielmetti, S.; Tamagnini, I.; Mora, D.; Minuzzo, M.; Scarafoni, A.; Arioli, S.; Hellman, J.; Karp, M.; Parini, C. Implication of an outer surface lipoprotein in adhesion of Bifidobacterium bifidum to Caco-2 cells. Appl. Environ. Microbiol. 2008, 74, 4695-4702. [CrossRef] [PubMed]

18. Wu, T.; Jiang, Q.; Wu, D.; Hu, Y.; Chen, S.; Ding, T.; Ye, X.; Liu, D.; Chen, J. What is new in lysozyme research and its application in food industry? A review. Food Chem. 2019, 274, 698-709. [CrossRef]

19. Callow, R.K.; Hart, P.D.A. Antibiotic Material from Bacillus licheniformis (Weigmann, emend. Gibson) Active Against Species of Mycobacteria. Nature 1946, 157, 334-335. [CrossRef] [PubMed]

20. Schindler, C.A.; Schuhardt, V.T. Lysostaphin: A New Bacteriolytic Agent For The Staphylococcus. Proc. Natl. Acad. Sci. USA 1964, 51, 414-421. [CrossRef]

21. Fleming, A. On a Remarkable Bacteriolytic Element Found in Tissues and Secretions. Proc. R. Soc. Lond. Ser. B Contain. Pap. A Biol. Character 1922, 93, 306-317.

22. Ragland, S.A.; Criss, A.K. From bacterial killing to immune modulation: Recent insights into the functions of lysozyme. PLoS Pathog. 2017, 13, e1006512. [CrossRef]

23. Ryu, M.; Park, J.; Yeom, J.H.; Joo, M.; Lee, K. Rediscovery of antimicrobial peptides as therapeutic agents. J. Microbiol. 2021, 59, 113-123. [CrossRef]

24. Yu, S.; Balasubramanian, I.; Laubitz, D.; Tong, K.; Bandyopadhyay, S.; Lin, X.; Flores, J.; Singh, R.; Liu, Y.; Macazana, C.; et al. Paneth Cell-Derived Lysozyme Defines the Composition of Mucolytic Microbiota and the Inflammatory Tone of the Intestine. Immunity 2020, 53, 398-416.e8. [CrossRef] [PubMed]

25. Zhou, C.; Fang, X.; Xu, J.; Gao, J.; Zhang, L.; Zhao, J.; Meng, Y.; Zhou, W.; Han, X.; Bai, Y.; et al. Bifidobacterium longum alleviates irritable bowel syndrome-related visceral hypersensitivity and microbiota dysbiosis via Paneth cell regulation. Gut Microbes 2020, 12, 1782156. [CrossRef] [PubMed]

26. Sun, X.; Hong, H.; Jia, S.; Liu, Y.; Luo, Y. Effects of phytic acid and lysozyme on microbial composition and quality of grass carp (Ctenopharyngodon idellus) fillets stored at 4 degrees C. Food Microbiol. 2020, 86, 103313. [CrossRef]

27. Zhang, B.; Tao, H.; Niu, X.; Li, S.; Chen, H.-Q. Lysozyme distribution, structural identification, and in vitro release of starch-based microgel-lysozyme complexes. Food Chem. 2017, 227, 137-141. [CrossRef]

28. Turner, M.S.; Hafner, L.M.; Walsh, T.; Giffard, P.M. Identification, characterisation and specificity of a cell wall lytic enzyme from Lactobacillus fermentum BR11. FEMS Microbiol. Lett. 2004, 238, 9-15. [CrossRef]

29. Birkeland, N.K. Cloning, molecular characterization, and expression of the genes encoding the lytic functions of lactococcal bacteriophage phi LC3: A dual lysis system of modular design. Can. J. Microbiol. 1994, 40, 658-665. [CrossRef] [PubMed]

30. Tenea, G.N.; Hurtado, P. Next-Generation Sequencing for Whole-Genome Characterization of Weissella cibaria UTNGt21O Strain Originated From Wild Solanum quitoense Lam. Fruits: An Atlas of Metabolites With Biotechnological Significance. Front. Microbiol. 2021, 12, 1240. [CrossRef] [PubMed]

31. Hu, S.P.; Li, J.J.; Dhar, N.; Li, J.P.; Chen, J.Y.; Jian, W.; Dai, X.F.; Yang, X.Y. Lysin Motif (LysM) Proteins: Interlinking Manipulation of Plant Immunity and Fungi. Int. J. Mol. Sci. 2021, 22, 3114. [CrossRef]

32. Chaput, C.; Labigne, A.; Boneca, I.G. Characterization of Helicobacter pylori lytic transglycosylases Slt and MltD. J. Bacteriol. 2007, 189, 422-429. [CrossRef] [PubMed]

33. Lewis, R.E.; Diekema, D.J.; Messer, S.A.; Pfaller, M.A.; Klepser, M.E. Comparison of Etest, chequerboard dilution and time-kill studies for the detection of synergy or antagonism between antifungal agents tested against Candida species. J. Antimicrob. Chemother. 2002, 49, 345-351. [CrossRef]

34. Derde, M.; Guérin-Dubiard, C.; Lechevalier, V.; Cochet, M.-F.; Jan, S.; Baron, F.; Gautier, M.; Vié, V.; Nau, F. Dry-Heating of Lysozyme Increases Its Activity against Escherichia coli Membranes. J. Agric. Food Chem. 2014, 62, 1692-1700. [CrossRef]

35. Liu, Z.; Li, J.; Wei, B.; Huang, T.; Xiao, Y.; Peng, Z.; Xie, M.; Xiong, T. Bacterial community and composition in Jiang-shui and Suan-cai revealed by high-throughput sequencing of $16 \mathrm{~S}$ rRNA. Int. J. Food Microbiol. 2019, 306, 108271. [CrossRef]

36. Dan, Z.; Mao, X.; Liu, Q.; Guo, M.; Zhuang, Y.; Liu, Z.; Chen, K.; Chen, J.; Xu, R.; Tang, J.; et al. Altered gut microbial profile is associated with abnormal metabolism activity of Autism Spectrum Disorder. Gut Microbes 2020, 11, 1246-1267. [CrossRef]

37. Namai, F.; Shigemori, S.; Ogita, T.; Sato, T.; Shimosato, T. Microbial therapeutics for acute colitis based on genetically modified Lactococcus lactis hypersecreting IL-1Ra in mice. Exp. Mol. Med. 2020, 52, 1627-1636. [CrossRef] [PubMed]

38. Brandao Gois, M.F.; Sinha, T.; Spreckels, J.E.; Vich Vila, A.; Bolte, L.A.; Weersma, R.K.; Wijmenga, C.; Fu, J.; Zhernakova, A.; Kurilshikov, A. Role of the gut microbiome in mediating lactose intolerance symptoms. Gut 2021. [CrossRef]

39. Castro-González, J.M.; Castro, P.; Sandoval, H.; Castro-Sandoval, D. Probiotic Lactobacilli Precautions. Front. Microbiol. 2019, 10. [CrossRef]

40. Costa, R.L.; Moreira, J.; Lorenzo, A.; Lamas, C.C. Infectious complications following probiotic ingestion: A potentially underestimated problem? A systematic review of reports and case series. BMC Complement. Altern. Med. 2018, 18, 329. [CrossRef] [PubMed] 
41. Niu, H.L.; Xiao, J.Y. The efficacy and safety of probiotics in patients with irritable bowel syndrome: Evidence based on 35 randomized controlled trials. Int. J. Surg. 2020, 75, 116-127. [CrossRef] [PubMed]

42. Yang, J.; Deng, Y.; Chu, H.; Cong, Y.; Zhao, J.; Pohl, D.; Misselwitz, B.; Fried, M.; Dai, N.; Fox, M. Prevalence and Presentation of Lactose Intolerance and Effects on Dairy Product Intake in Healthy Subjects and Patients With Irritable Bowel Syndrome. Clin. Gastroenterol. Hepatol. 2013, 11, 262-268.e261. [CrossRef]

43. Voisin, M.R.; Borici-Mazi, R. Anaphylaxis to supplemental oral lactase enzyme. Allergy Asthma Clin. Immunol. 2016, 12 , 66. [CrossRef]

44. Oak, S.J.; Jha, R. The effects of probiotics in lactose intolerance: A systematic review. Crit Rev. Food Sci. Nutr. 2019, 59, 1675-1683. [CrossRef]

45. Hertzler, S.R.; Savaiano, D.A. Colonic adaptation to daily lactose feeding in lactose maldigesters reduces lactose intolerance. Am. J. Clin. Nutr. 1996, 64, 232-236. [CrossRef] [PubMed]

46. Savaiano, D.A.; Ritter, A.J.; Klaenhammer, T.R.; James, G.M.; Longcore, A.T.; Chandler, J.R.; Walker, W.A.; Foyt, H.L. Improving lactose digestion and symptoms of lactose intolerance with a novel galacto-oligosaccharide (RP-G28): A randomized, double-blind clinical trial. Nutr. J. 2013, 12, 160. [CrossRef] [PubMed]

47. Troise, A.D.; Bandini, E.; De Donno, R.; Meijer, G.; Trezzi, M.; Fogliano, V. The quality of low lactose milk is affected by the side proteolytic activity of the lactase used in the production process. Food Res. Int. 2016, 89, 514-525. [CrossRef]

48. Staudacher, H.M.; Lomer, M.C.E.; Farquharson, F.M.; Louis, P.; Fava, F.; Franciosi, E.; Scholz, M.; Tuohy, K.M.; Lindsay, J.O.; Irving, P.M.; et al. A Diet Low in FODMAPs Reduces Symptoms in Patients With Irritable Bowel Syndrome and A Probiotic Restores Bifidobacterium Species: A Randomized Controlled Trial. Gastroenterology 2017, 153, 936-947. [CrossRef]

49. He, T.; Venema, K.; Priebe, M.G.; Welling, G.W.; Brummer, R.J.; Vonk, R.J. The role of colonic metabolism in lactose intolerance. Eur. J. Clin. Investig. 2008, 38, 541-547. [CrossRef] [PubMed]

50. He, T.; Priebe, M.G.; Harmsen, H.J.M.; Stellaard, F.; Sun, X.; Welling, G.W.; Vonk, R.J. Colonic Fermentation May Play a Role in Lactose Intolerance in Humans. J. Nutr. 2006, 136, 58-63. [CrossRef]

51. Heiman, M.L.; Greenway, F.L. A healthy gastrointestinal microbiome is dependent on dietary diversity. Mol. Metab. 2016, 5, 317-320. [CrossRef]

52. Xie, X.; Cane, D.E. Stereospecific Formation of Z-Trisubstituted Double Bonds by the Successive Action of Ketoreductase and Dehydratase Domains from trans-AT Polyketide Synthases. Biochemistry 2018, 57, 3126-3129. [CrossRef] [PubMed]

53. Yang, S.; Xie, X.; Ma, J.; He, X.; Li, Y.; Du, M.; Li, L.; Yang, L.; Wu, Q.; Chen, W.; et al. Selective Isolation of Bifidobacterium From Human Faeces Using Pangenomics, Metagenomics, and Enzymology. Front. Microbiol. 2021, 12, 649698. [CrossRef] [PubMed]

54. Bolger, A.M.; Lohse, M.; Usadel, B. Trimmomatic: A flexible trimmer for Illumina sequence data. Bioinformatics 2014, 30, 2114-2120. [CrossRef] [PubMed] 